\title{
Aging Thermal Treatment in the Inconel 725 Brazed Incorporating Tungsten Nanoparticles
}

\author{
H. M. Hdz-García, ${ }^{1}$ R. Muñoz-Arroyo, ${ }^{1}$ A. I. Martinez, ${ }^{2}$ M. A. González, ${ }^{3,4}$ \\ E. E. Granda-Gutiérrez, ${ }^{1}$ J. L. Acevedo-Dávila, ${ }^{1}$ M. Castro-Roman, ${ }^{2}$ and F. García-Vázquez ${ }^{1}$ \\ ${ }^{1}$ Corporación Mexicana de Investigación en Materiales, S.A. de C.V., Ciencia y Tecnología No. 790, \\ Fraccionamiento Saltillo 400, 25290 Saltillo, COAH, Mexico \\ ${ }^{2}$ Center for Research and Advanced Studies of the National Polytechnic Institute, Cinvestav-Saltillo, \\ 25900 Ramos Arizpe, COAH, Mexico \\ ${ }^{3}$ Departamento de Ingeniería de Proyectos, CUCEI, Universidad de Guadalajara, Jose Guadalupe Zuno 48, \\ Los Belenes, 45101 Zapopan, JAL, Mexico \\ ${ }^{4}$ Consejo Nacional de Ciencia y Tecnología, Dirección de Cátedras, Avenida Insurgentes Sur 1582, \\ Colonia Crédito Constructor, 03940 Delegación Benito Juárez, DF, Mexico
}

Correspondence should be addressed to H. M. Hdz-García; hmanuelhdz@comimsa.com and A. I. Martinez; mtz.art@gmail.com Received 14 September 2015; Revised 28 November 2015; Accepted 6 December 2015

Academic Editor: Hongbin Bei

Copyright (C) 2016 H. M. Hdz-García et al. This is an open access article distributed under the Creative Commons Attribution License, which permits unrestricted use, distribution, and reproduction in any medium, provided the original work is properly cited.

Fractures in blade sections of Inconel 725 were impregnated with tungsten nanoparticles and jointed by the brazing process. In order to evaluate their effect over the microstructure, aging thermal treatments at $750^{\circ} \mathrm{C}$ for $2,6,10$, and $14 \mathrm{~h}$ were done. BNi- 9 was selected as brazing filler metal and was characterized by scanning electron microscopy and X-ray fluorescence. Before brazing, the fractures were impregnated with a mixture of tungsten NPs in ethanol. Measurements of Vickers microhardness showed an increase in the melting zone of samples with aging thermal treatment for $14 \mathrm{~h}$, which is attributed to the precipitation of the $\gamma^{\prime}$ phase with a typical size of $c a .100 \mathrm{~nm}$. Likewise, the tungsten NPs modified the size and morphology of Cr-Ni eutectics into finer and uniformly distributed microstructures.

\section{Introduction}

Nickel-base alloys are used for gas turbines in coal industry, chemical processes, and other specific applications. These alloys are corrosion resistant at high temperatures and are used at excessive loads approaching $80 \%$ close to incipient melting temperature. Comparatively, nickel-based alloys can obtain a major fraction of the strength possessed by other engineered alloys via precipitating the $\mathrm{Ni}_{3}(\mathrm{Al}, \mathrm{Ti}) \gamma^{\prime}$ phase [1]. These precipitates are resistant to overaging at $425^{\circ} \mathrm{C}$ under several cycle fatigues [1-3]. It has been found that clusters of $\gamma^{\prime}$ decrease the diffusion rate of $\mathrm{B}, \mathrm{C}, \mathrm{Cr}$, and $\mathrm{W}$ and likewise dislocations movement and increase the strengthening of nickel-base alloys at high temperatures [1]. Cr, Al, and $\mathrm{Y}$ are essential elements that increase the oxidation and corrosion resistance of nickel-base alloys [1-3].
In the case of polycrystalline superalloys, additions of $\mathrm{Zr}$ and $\mathrm{B}$ increase the cohesion and strengthening of grain boundary by precipitation hardening mechanism $[4,5]$. It has been found that carbide precipitates grow as a shaped necklace along the grain boundaries, thus decreasing their slip. It is particularly important to avoid $\mu$ and $\sigma$ phases (known as TPC), the chemical composition of which is $\mathrm{Cr}$ and Mo. If there is a considerable formation of such phases during the thermal cycle, brazed Inconel 725 will become more susceptible to corrosion, and the mechanical properties will be detrimentally affected, giving place to fracture initiation [6]. Additionally, rhodium, a relatively expensive element, has been used for improvement of fracture toughness by modifying intermetallics [7]. On the other hand, industrial gas turbines blades fail during service due to the operation conditions in aggressive environments. These conditions modify 
the microstructure, giving place to excessive growth of carbides at grain boundaries, formation of intermetallics, eutectic phases with low melting point, precipitations of Laves phases, growth of $\mu$ and $\sigma$ phases, and liquation phenomena in the grain boundaries [8].

Several ways for blade repairing have been proposed; one of them is the brazing process and a subsequent aging thermal treatment. The brazing process is an alternative technique for joining components made from special alloys by simply joining two base materials with a filler metal [9-11], although brazed joints often contain hard and brittle intermetallic phases, which decrease the mechanical and corrosion properties of the bonding areas [12-15]. An alternative to prevent the formation of intermetallics as a function of dissolution and homogenization time is the use of transient liquid phase (TLP) bonding with a thermal posttreatment $[9,10,12,16,17]$. This procedure consists in a complete isothermal solidification of the TLP that exists temporarily during the brazing process. It has been reported that tungsten reduces the size of borides, modifies the intermetallics, and forms a W-rich diffusion barrier that changes the distribution of eutectics in alloys with high content of $\mathrm{Cr}$ and $\mathrm{Ni}$ [18-22]. Given these characteristics, the incorporation of tungsten nanoparticles (W-NP) in the brazing process of nickel-base alloys may provide valuable properties in joining areas. To the best of our knowledge, there are no published data on the role of W-NP in brazed nickel-base alloys. The aim of this work is to study the incorporation of W-NP in the brazing process of Inconel 725. It was found that the use of W-NP modifies the eutectic and intermetallic phases in the joining areas of Inconel 725.

\section{Experimental Procedure}

2.1. Characterization and Impregnation of Tungsten NPs on the Fractured Blade of Inconel 725. The selected filler metal was BNi-9 (Colmonoy) due to the fact that it has two key elements: (1) nickel, the main element of the Inconel 725, and (2) its high content of boron, which may both activate efficiently the diffusion mechanism in the melting zone and promote the formation of $\mathrm{Cr}$ borides. The microstructure was characterized by scanning electron microscopy (SEM) in a Philips XL30 microscope. The chemical composition was determined by X-ray fluorescence in a Bruker S4 Pioneer spectrometer. For the brazing process and the effects of spherical tungsten NPs ( $80 \mathrm{~nm}$, Nanospyring), fractures were induced in Inconel 725 blades sections with notch before bending them with a mechanical testing machine. This process forms many microcracks by coalescence and growth of micropores. The obtained fractures were inspected by SEM and their chemical composition was analyzed by spark atomic emission spectrometry in a Metrolab M11 spectrometer.

For the impregnation of tungsten NPs on the fractured blades, firstly, the Inconel 725 fractured specimens were ultrasonically cleaned with ethanol for $15 \mathrm{~min}$. Separately, the tungsten NPs were dispersed five times in ethanol using a mixture of $0.5 \mathrm{~g}$ of tungsten NPs in $100 \mathrm{~mL}$ of ethanol and sonicated for $1 \mathrm{~h}$. Subsequently, the cleaned fracture specimens were placed into the dispersed tungsten NPs and sonicated for

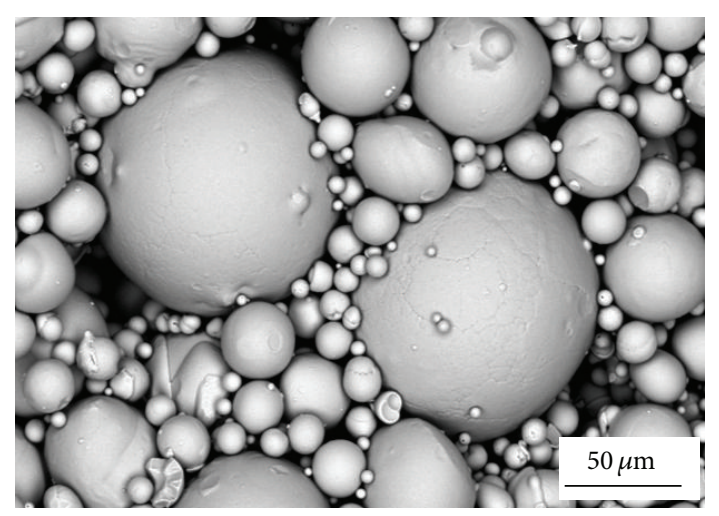

FIGURE 1: SEM image of BNi-9 filler metal.

$30 \mathrm{~min}$. The sonication process promotes the incorporation of tungsten NPs into the microcracked fractures.

2.2. Effect of Tungsten NPs on the Fractured Surface of Inconel 725 without Filler Metal. In order to determine the reactivity of the tungsten NPs on Inconel 725 fractures, the impregnated fractures were exposed, without the filler metal paste, at $1150^{\circ} \mathrm{C}$ for $2 \mathrm{~h}$ using heating/cooling rates of $10^{\circ} \mathrm{C} / \mathrm{min}$ in a sealed tube furnace under Ar (99.999\%) gas flow of $200 \mathrm{~mL} /$ $\mathrm{min}$. The resulting samples were characterized by SEM.

\subsection{Brazing and Aging Thermal Treatment in Fractured} Inconel 725. In order to evaluate the effect of tungsten NPs in the brazing process of Inconel 725, the brazing process was conducted in a tightly sealed tube furnace under Ar gas flow of $200 \mathrm{~mL} / \mathrm{min}$ at a pressure of $10^{-3}$ Torr. The brazing temperature used was of $1150^{\circ} \mathrm{C}$ for $2 \mathrm{~h}$; the heating and cooling rates were fixed at $10^{\circ} \mathrm{C} / \mathrm{min}$. The paste filler metal was spread on both types of fracture specimens, namely, with and without dispersed tungsten NPs. This operation was followed by the manual joining of the fracture surface counterparts in such a way that the gap distance between the joined surfaces was $c a$. $1 \mathrm{~mm}$. During the brazing tests, a soldering flux was not used because after fracturing the specimens were immediately cleaned and brazed.

After brazing process, the specimens were aged at $750^{\circ} \mathrm{C}$ for $2,6,10$, and $14 \mathrm{~h}$ in vacuum at $10^{-3}$ Torr and cooled down at open atmosphere. The samples were characterized by SEM and energy-dispersive X-ray spectroscopy (EDX), and the microhardness was evaluated by Vickers hardness tester, Wilson Instruments Tukon $2100 \mathrm{~B}$, using a load of $250 \mathrm{~g}$ with a pyramidal 10 -micron indenter. Microhardness measurements were performed in each zone, namely, melting zone (MZ), isothermal zone (IZ), and base metal (BM). Finally, $\mathrm{MZ}$ of the sample aged for $14 \mathrm{~h}$ was characterized by high resolution transmission electron microscopy (HR-TEM) in FEI Titan microscope and EDX.

\section{Results and Discussion}

3.1. Characterization of Filler Metal and Inconel 725 Specimens. As can be appreciated in the SEM image of Figure 1, 


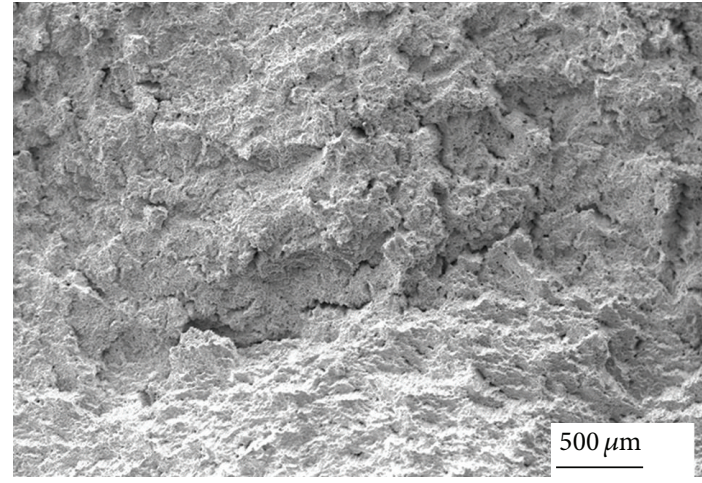

(a)

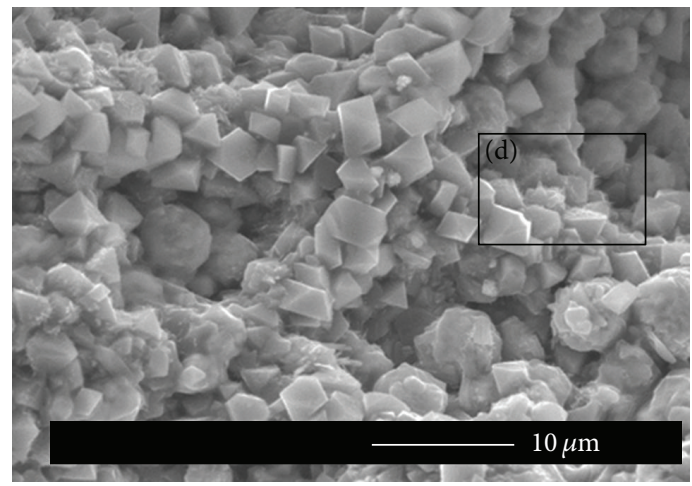

(c)

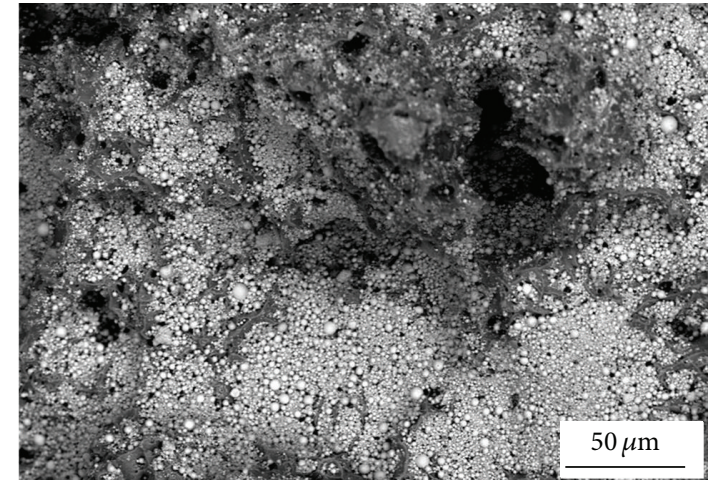

(b)

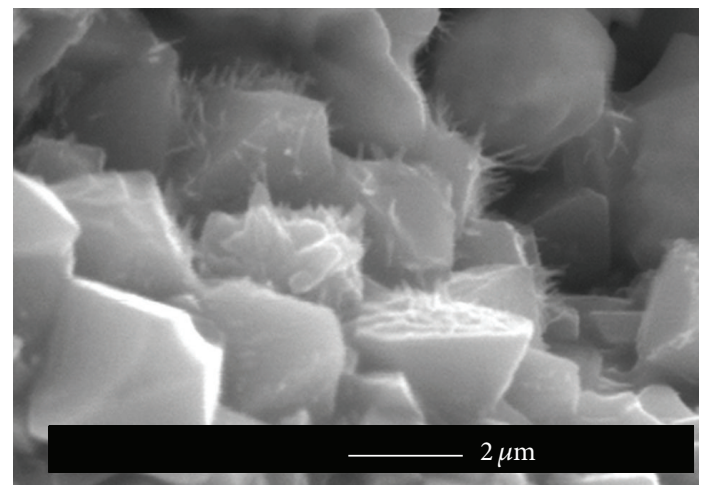

(d)

FIGURE 2: SEM micrographs of the fractured surface before and after the W-NPs impregnation process. (a) Fractured surface as-received. (b) Sonicated fracture with W-NPs. (c) Interaction of W-NPs with the Inconel 725 annealed at $1150^{\circ} \mathrm{C}$ for $2 \mathrm{~h}$. (d) A zoom of the area depicted in (c) shows prismatic crystals with nanowhisker growth on the surface.

the agglomerates of paste filler metal have sizes between 10 and $50 \mu \mathrm{m}$. This is a technical problem because the paste cannot penetrate inside small microcracks or micropores before conducting the brazing process. Besides, it has been reported that the TLP bonding step is short [13], given that the melting of the interlayer lasts less than a second to several seconds, and the step of melting back of the substrate takes seconds to minutes. This time is important because the TLP step may activate the capillary process with surface liquid of NPs that were previously deposited inside microcracks or micropores [22]. Studies of phase modifications or thermal events as a function of brazing temperature without mixing with filler metal have been reported [10, 22]. The chemical composition of the filler metal is presented in Table 1. On the other hand, Table 2 summarizes the chemical composition of the Inconel 725 blade. A characteristic of this blade is the content of $\mathrm{Nb}$ and $\mathrm{Al}$ that can influence the precipitation of the strengthening phases during aging thermal treatment.

3.2. Reactivity of Tungsten NPs on the Fractured Samples of Inconel 725 without Filler Metal. A preliminary step to the brazing process, the behavior of W-NPs on the Inconel 725 specimens, was evaluated by SEM. Figure 2 shows a sequence of SEM micrographs of the fractured surface before and after
TABLE 1: Chemical composition (wt. \%) of BNi-9 paste filler metal.

\begin{tabular}{lcccccccr}
\hline Element & $\mathrm{B}$ & $\mathrm{Si}$ & $\mathrm{C}$ & $\mathrm{Fe}$ & $\mathrm{Na}$ & $\mathrm{Ca}$ & $\mathrm{Cr}$ & $\mathrm{Ni}$ \\
\hline wt. \% & 2.57 & 0.041 & 1.16 & 0.35 & 0.14 & 0.22 & 16.32 & $\mathrm{Bal}$. \\
\hline
\end{tabular}

the tungsten NPs impregnation process. Figure 2(a) shows some microcracks on the fractured surface and micropores of different sizes. A fractured surface with an impregnation of spherical W-NPs without paste filler metal is shown in Figure 2(b), where numerous spherical NPs are distinguished. Meanwhile, Figure 2(c) shows the result of the interaction of W-NPs with Inconel 725 after an annealing process at $1150^{\circ} \mathrm{C}$ for $2 \mathrm{~h}$. As can be observed, the spherical NPs become faceted tungsten particles, which are originated by the preferential growth of the base metal. A zoom shown in Figure 2(d) shows the development of nanowhiskers on the surface of faceted tungsten particles. This fact requires a supersaturated solution ( $S$ ) on the droplet (liquid); it can be schematized by the following equation shown by Borovik and Fisenko [23]:

$$
S=\frac{n}{n_{1}(T)},
$$

where $n$ is the number density of A-type molecules in the solution and $n_{1}(T)$ is the number density of such molecules 
TABLE 2: Chemical composition (wt. \%) of Inconel 725.

\begin{tabular}{lcccccccccccc}
\hline $\mathrm{Ni}$ & $\mathrm{Cr}$ & $\mathrm{Mo}$ & $\mathrm{Nb}$ & $\mathrm{Ti}$ & $\mathrm{Al}$ & $\mathrm{C}$ & $\mathrm{Mn}$ & $\mathrm{Si}$ & $\mathrm{P}$ & $\mathrm{S}$ & $\mathrm{Co}$ & $\mathrm{Fe}$ \\
\hline 55.20 & 19.00 & 2.20 & 2.86 & 1.05 & 0.18 & 0.027 & 0.20 & 0.15 & 0.012 & 0.009 & 8.60 & Balance \\
\hline
\end{tabular}
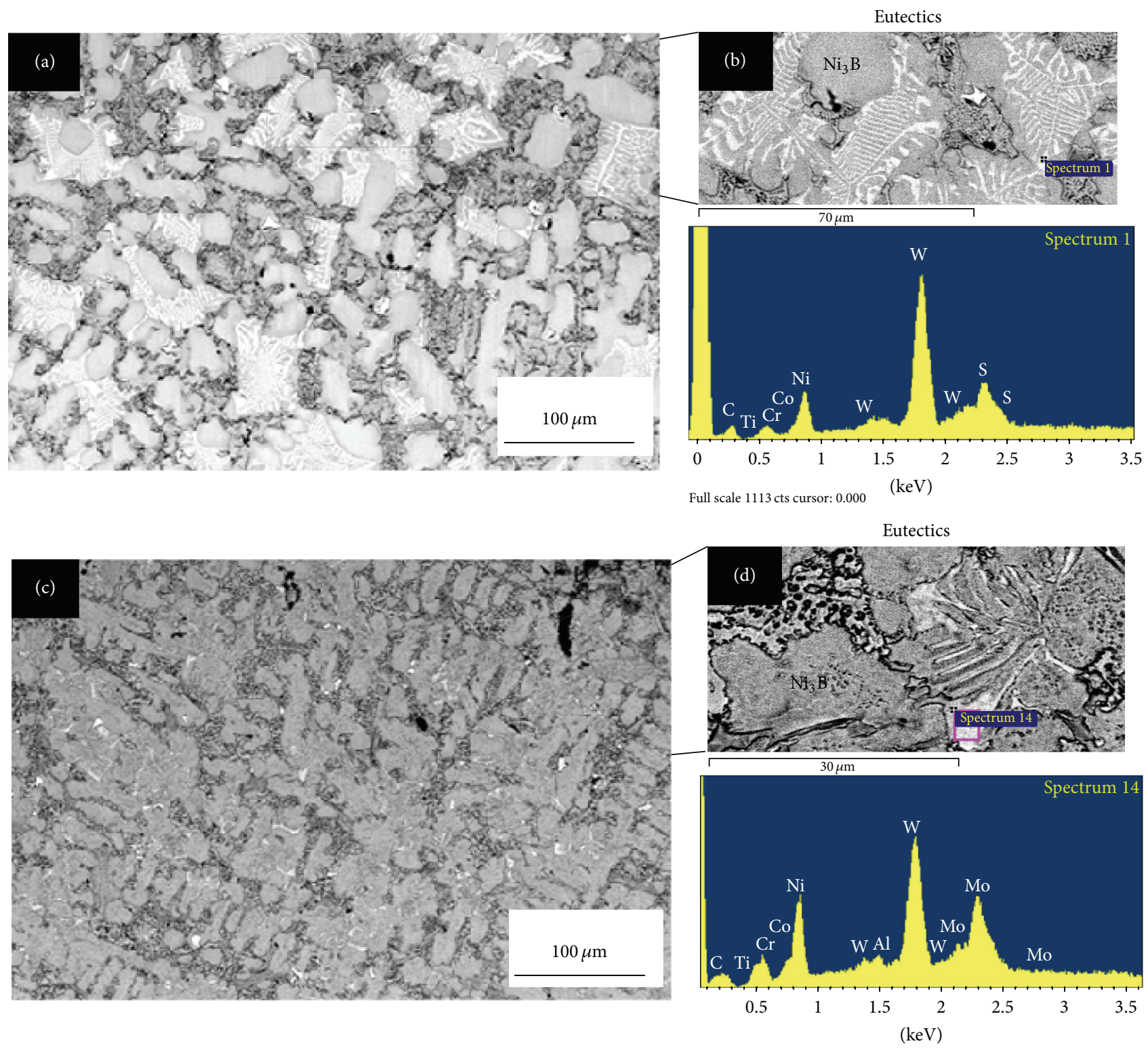

Full scale 1174 cts cursor: 0.798 ( $257 \mathrm{cts})$

Figure 3: SEM images of brazed specimens using W-NPs and BNi-9 filler metal aged at $750^{\circ} \mathrm{C}$ for (a) $2 \mathrm{~h}$ and (c) $14 \mathrm{~h}$. (b) A zoom of (a) shows the eutectics, $\mathrm{Ni}_{3} \mathrm{~B}$ zones, and their EDX spectrum. (d) A zoom of (c) shows the eutectics, $\mathrm{Ni}_{3} \mathrm{~B}$ zones, and their EDX spectrum.

corresponding to the equilibrium solubility of substance A in the droplet material $B$ at a given temperature $T$. In this case, a small liquid amount of base metal is present on the surface of the tungsten faceted particles, where the liquid is spread if the solid tungsten particles are wetted. It means that the contact angle is less than 90 degrees, and the magnitude of the liquidvapor surface tension $\left(\gamma_{l v}\right)$ is favorably low. The microcracks impregnated with W-NPs can be thought of as countless capillary tubes through which the liquid phase can rise, in analogy with the tube-bundle theory presented by Poirier and Geiger [24].

3.3. Brazing and Aging Thermal Treatment of the Fractured Blade of Inconel 725. Comparatively, the areas joined by the brazing process using both W-NPs and BNi-9 filler metal aged at $750^{\circ} \mathrm{C}$ for 2 and $14 \mathrm{~h}$ are shown in Figure 3. The SEM images and the chemical composition determined by EDX of a specimen aged for $2 \mathrm{~h}$ are shown in Figures 3(a) and 3(b); it 


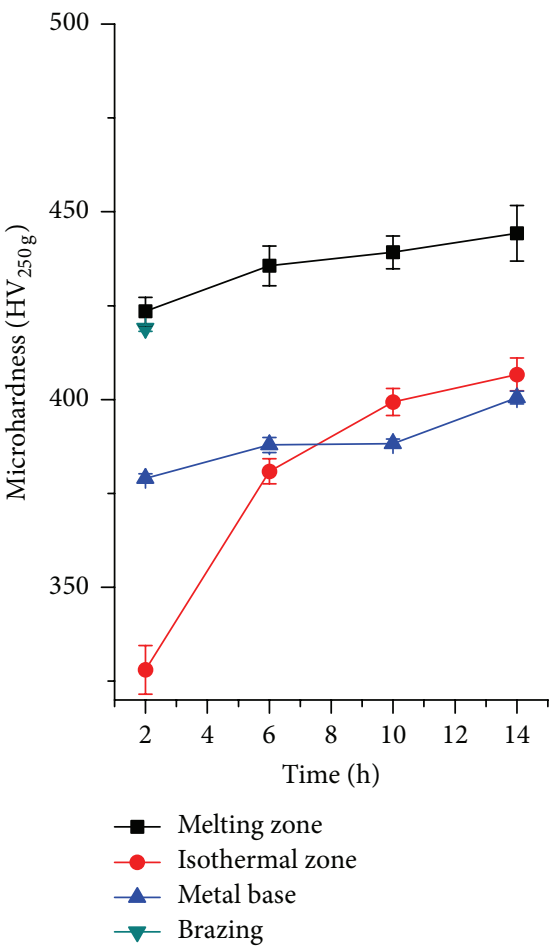

(a)

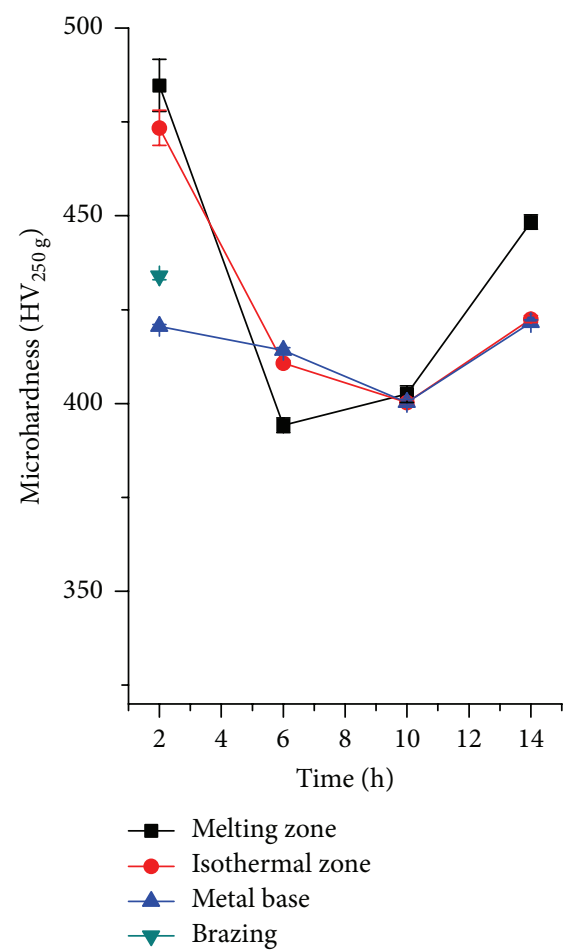

(b)

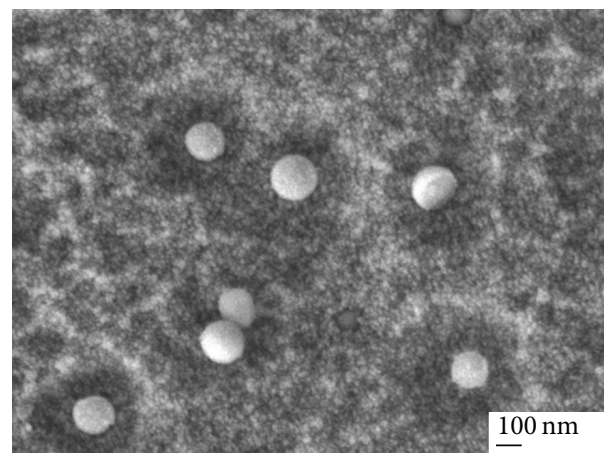

(c)

Figure 4: (a) Variation of the microhardness in the samples without and (b) with tungsten NPs as function of aging time at $750^{\circ} \mathrm{C}$. (c) SEM micrograph of the precipitates obtained in the sample with W-NPs at $750^{\circ} \mathrm{C}$ for $14 \mathrm{~h}$ in MZ.

can be observed that the eutectics have shown a lamellar morphology with a size near to $100 \mu \mathrm{m}$. Additionally, small zones of $\mathrm{Ni}_{3} \mathrm{~B}$ precipitates are observed. In contrast, when the aging time increases to $14 \mathrm{~h}$, the eutectic structures are smaller, and $\mathrm{Ni}_{3} \mathrm{~B}$ regions are larger; see Figure 3(c). The chemical composition of eutectics consists of a high intensity peak of tungsten; see the EDX spectrum of Figure 3(d). It has been reported that the use of W-NPs in the brazing process interferes with the diffusion of $\mathrm{Cr}$ and $\mathrm{Ni}$ and avoids the eutectic growth [22]. In contrast, without the use of W-NPs, this diffusion barrier can dissolve the matrix with a major content of $\mathrm{Al}$ and $\mathrm{Nb}$ and yields the precipitation of $\gamma^{\prime}$ phase [6].

In order to investigate the influence of W-NPs on the mechanical properties of the brazed joints, microindentation hardness tests were performed near the bonding areas.
Figure 4(a) shows the microhardness of samples joined without the addition of W-NPs. It can be seen that the microhardness increases as time rises in different zones, especially in $\mathrm{MZ}$, where the microhardness increases due to the development with aging time of eutectic structures. This suggests that boron from the filler metal and the aging time increase the microhardness of MZ. The formation of large eutectic structures in the bonding zone gives hard and brittle brazed joints, which will deteriorate the mechanical and corrosion resistant properties [25]. A similar slow increase is observed between brazing and BM.

For the brazed joints using W-NPs as additive, the microhardness is shown in Figure 4(b). It is observed that the microhardness is very high at $2 \mathrm{~h}$ in both the IZ and MZ; it is due to the large size of eutectics in these zones. In contrast, 


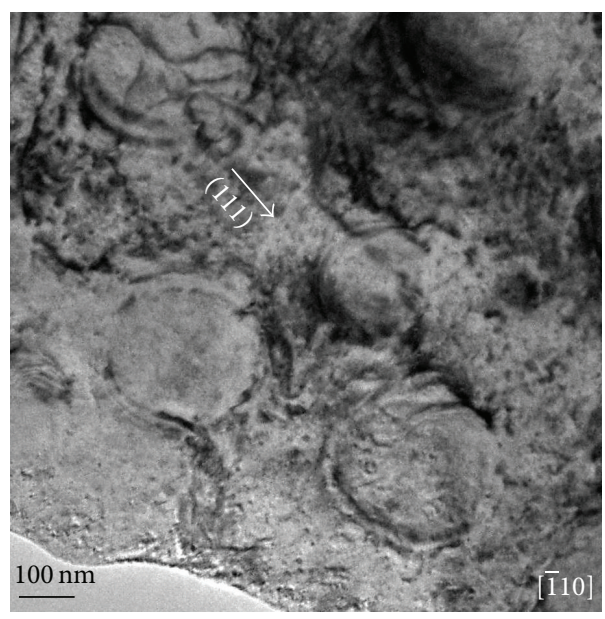

(a)

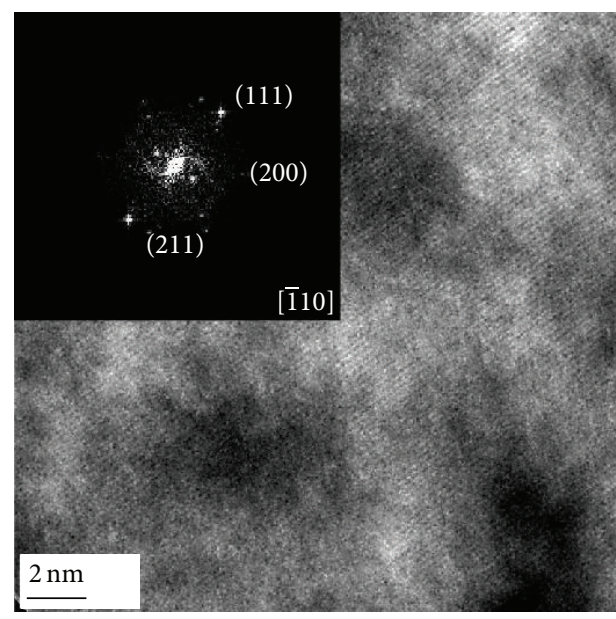

(b)

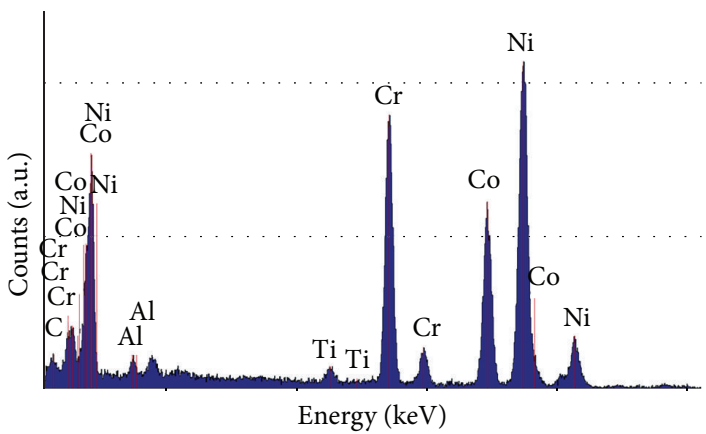

(c)

FIGURE 5: (a) TEM image of spherical $\gamma^{\prime}$ precipitates in the [110] zone axis. (b) HR-TEM image of a crystallite of $\gamma^{\prime}$ phase. Inset in (b) shows the FFT of the crystalline particle of $\gamma^{\prime}$ and (c) EDX of $\gamma^{\prime}$ particles.

at $6 \mathrm{~h}$ of aging, the microhardness decreases in both the IZ and MZ; it is because of a finer size of the eutectic structures. Otherwise, for $10 \mathrm{~h}$ of aging, it is noticeable that the three zones reach the same values of microhardness of ca. $400 \mathrm{HV}$; it could be due to a slight solid solubility of $\gamma^{\prime}$ in all the zones. However, an increase to $c a .418 \mathrm{HV}$ is observed at $14 \mathrm{~h}$ of aging for both IZ and BM.

It has been reported that higher strengths can be observed in the solder layers of reactive joints when finer microstructures are present [26]. Thereby, in the case of the BM, a hardening effect occurs for $14 \mathrm{~h}$ which is attributed to the precipitation of spherical intermetallics of $\sim 100 \mathrm{~nm}$ in size and which corresponds to $\gamma^{\prime}$ phase; see Figure 4(c) [8]. Figure 4(c) displays SEM image of spheroidal precipitates obtained at $750^{\circ} \mathrm{C}$ for $14 \mathrm{~h}$ in $\mathrm{MZ}$. This finding indicates two events that promote the W-NPs. The first one indicates that the W-NPs form a diffusion barrier that avoids the growth of intermetallics and eutectics. Therefore, the development of these phases depends on the content of $\mathrm{Cr}$ and $\mathrm{Ni}$, which may diffuse from BM to MZ. The second event is the reduction of the content of $\mathrm{Cr}$ and $\mathrm{Ni}$ that do not interfere in phase stability of $\gamma-\gamma^{\prime}$ in MZ. In summary, the addition of W-NPs diminishes the diffusion process in the three zones (MZ, IS, and BM). Nevertheless, the best result is obtained at $10 \mathrm{~h}$ of aging in presence of W-NPs; it is because of the fact that the microhardness in the joining zone is similar to the base metal.

Figure 5(a) shows HR-TEM image of the precipitates obtained at $750^{\circ} \mathrm{C}$ for $14 \mathrm{~h}$. In the inset a fast Fourier transform (FFT) of the squared area is shown in Figure 5(b); here the spots are indexed to the cubic structure of $\gamma^{\prime}$. Likewise, these precipitates consist mainly of $\mathrm{Ni}, \mathrm{Al}$, and $\mathrm{Ti}$ according to their EDX microanalysis shown in Figure 5(c); this fact confirms that the microhardness is directly related to hardening phenomenon that took place during the aging thermal treatment.

\section{Conclusions}

Within the framework of the experimental conditions used here, it was shown that, in absence of filler metal, the faceted tungsten particles on the fractured samples are substrates for the growth of nanowhiskers; this phenomenon requires further studies. It was shown that the aging thermal treatment at $750^{\circ} \mathrm{C}$ for $14 \mathrm{~h}$ influences positively the melting zone given that the impregnation of fractures with tungsten NPs leads to the development of finer intermetallics and eutectics. This is because the presence of tungsten diminishes the diffusion of $\mathrm{Cr}$ and $\mathrm{Ni}$ and avoids the development of larger eutectics. Additionally, the presence of tungsten NPs in the brazing 
process does not interfere with precipitation of $\gamma^{\prime}$ phase. Therefore, the addition of tungsten NPs in the brazing process of Inconel 725 is of particular interest because it can reduce the size of intermetallics and eutectics. The fine and well distributed microstructure together with the precipitation of $\gamma^{\prime}$ phase in the melting zone can improve the mechanical properties of the Inconel alloy. Finally, the addition of tungsten NPs in the brazing process is an attractive modification for repairing special components of nickel-base alloys.

\section{Conflict of Interests}

The authors declare that there is no conflict of interests regarding the publication of this paper.

\section{Acknowledgments}

The authors wish to express their gratitude for the National Council of Science and Technology (CONACYT) and Mexican Corporation for Materials Research (COMIMSA).

\section{References}

[1] D. P. Pope and S. S. Ezz, "Mechanical properties of $\mathrm{Ni}_{3} \mathrm{AI}$ and nickel-base alloys with high volume fraction of $\gamma^{\prime}$," International Metals Reviews, vol. 29, pp. 136-167, 1984.

[2] E. L. Hibner, H. W. Sizek, and S. K. Mannan, "Elevated temperature tensile and creep rupture properties of Inconel alloy 725," in Superalloys 718,625,706 and Various Derivatives, E. A. Loira, Ed., pp. 491-501, The Minerals, Metals \& Materials Society, Warrendale, Pa, USA, 1997.

[3] R. C. Reed, The Superalloys, Fundamentals and Applications, Cambridge University Press, New York, NY, USA, 2006.

[4] T. J. Garosshen, T. D. Tillman, and G. P. McCarthy, "Effects of B, $\mathrm{C}$, and $\mathrm{Zr}$ on the structure and properties of a $\mathrm{P} / \mathrm{M}$ nickel base superalloy," Metallurgical Transactions A, vol. 18, no. 1, pp. 6977, 1987.

[5] H.-E. Huang and C.-H. Koo, "Effect of zirconium on microstructure and mechanical properties of cast fine-grain CM 247 LC superalloy," Materials Transactions, vol. 45, no. 2, pp. 554561, 2004.

[6] J. N. DuPont, J. C. Lippold, and S. D. Kiser, Welding Metallurgy and Weldabilidy of Nickel Based Alloys, John Wiley \& Sons, Hoboken, NJ, USA, 2009.

[7] D. McGuire, X. Huang, D. Nagy, and W. Chen, "Effect of tungsten addition on the nucleation of borides in wide gap brazed joint," Journal of Engineering for Gas Turbines and Power, vol. 132, no. 6, Article ID 062101, 2010.

[8] M. A. González, D. I. Martínez, A. Pérez, H. Guajardo, and A. Garza, "Microstructural response to heat affected zone cracking of prewelding heat-treated Inconel 939 superalloy," Materials Characterization, vol. 62, no. 12, pp. 1116-1123, 2011.

[9] M. Abdelfatah and O. A. Ojo, "Formation of eutectic-type microconstituent during transient liquid phase bonding of nickel: influence of process parameters," Materials Science and Technology, vol. 25, no. 1, pp. 61-67, 2009.

[10] A. Ghoneim and O. A. Ojo, "Microstructure and mechanical response of transient liquid phase joint in Haynes 282 superalloy," Materials Characterization, vol. 62, no. 1, pp. 1-7, 2011.

[11] R. M. Do Nascimento, A. E. Martinelli, A. J. De Almeida Buschinelli, U. Reisgen, and J. Remmel, "Microstructure of brazed joints between mechanically metallized $\mathrm{Si}_{3} \mathrm{~N}_{4}$ and stainless steel," Journal of Materials Science, vol. 40, no. 17, pp. 45494556, 2005.

[12] V. Jalilvand, H. Omidvar, H. R. Shakeri, and M. R. Rahimipour, "Microstructural evolution during transient liquid phase bonding of Inconel 738LC using AMS 4777 filler alloy," Materials Characterization, vol. 75, pp. 20-28, 2013.

[13] G. O. Cook III and C. D. Sorensen, "Overview of transient liquid phase and partial transient liquid phase bonding," Journal of Materials Science, vol. 46, no. 16, pp. 5305-5323, 2011.

[14] H. van Esch and J. T. Stover, Review of the State of the Art of High-Temperature Brazing for Combustion Turbine Components, Electric Power Research Institute (EPRI), Palo Alto, Calif, USA, 2003.

[15] M. A. Arafin, M. Medraj, D. P. Turner, and P. Bocher, "Transient liquid phase bonding of Inconel 718 and Inconel 625 with BNi2: modeling and experimental investigations," Materials Science and Engineering A, vol. 447, no. 1-2, pp. 125-133, 2007.

[16] M. Mosallaee, A. Ekrami, K. Ohsasa, and K. Matsuura, "Microstructural evolution in the transient-liquid-phase bonding area of IN-738LC/BNi-3/IN-738LC," Metallurgical and Materials Transactions A, vol. 39, no. 10, pp. 2389-2402, 2008.

[17] M. Pouranvari, A. Ekrami, and A. H. Kokabi, "Effect of bonding temperature on microstructure development during TLP bonding of a nickel base superalloy," Journal of Alloys and Compounds, vol. 469, no. 1-2, pp. 270-275, 2009.

[18] H. M. Hdz-García, A. I. Martinez, R. Muñoz-Arroyo, J. L. Acevedo-Dávila, F. García-Vázquez, and F. A. Reyes-Valdes, "Effects of silicon nanoparticles on the transient liquid phase bonding of 304 stainless steel," Journal of Materials Science and Technology, vol. 30, no. 3, pp. 259-262, 2014.

[19] C.-J. Park, M.-K. Ahn, and H.-S. Kwon, "Influences of Mo substitution by $\mathrm{W}$ on the precipitation kinetics of secondary phases and the associated localized corrosion and embrittlement in 29\% Cr ferritic stainless steels," Materials Science and Engineering A, vol. 418, no. 1-2, pp. 211-217, 2006.

[20] J. Michalska and M. Sozańska, "Qualitative and quantitative analysis of $\sigma$ and $\chi$ phases in 2205 duplex stainless steel," Materials Characterization, vol. 56, no. 4-5, pp. 355-362, 2006.

[21] S.-B. Kim, K.-W. Paik, and Y.-G. Kim, "Effect of Mo substitution by $\mathrm{W}$ on high temperature embrittlement characteristics in duplex stainless steels," Materials Science and Engineering A, vol. 247, no. 1-2, pp. 67-74, 1998.

[22] H. M. Hdz-García, M. I. Pech-Canul, R. Muñoz-Arroyo et al., "304 Stainless steel brazing incorporating tungsten nanoparticles," Journal of Materials Processing Technology, vol. 215, pp. 1-5, 2015.

[23] F. N. Borovik and S. P. Fisenko, "Kinetics of nanowhisker growth via the vapor-liquid-solid mechanism," Technical Physics Letters, vol. 33, no. 2, pp. 151-153, 2007.

[24] D. R. Poirier and G. H. Geiger, Transport Phenomena in Materials Processing, The Minerals, Metals and Materials Society, Warrendale, Pa, USA, 1994.

[25] S. Y. Chang, C. C. Jain, T. H. Chuang, L. P. Feng, and L. C. Tsao, "Effect of addition of $\mathrm{TiO}_{2}$ nanoparticles on the microstructure, microhardness and interfacial reactions of Sn3.5AgXCu solder," Materials and Design, vol. 32, no. 10, pp. 4720-4727, 2011.

[26] J. Wang, E. Besnoin, A. Duckham et al., "Joining of stainlesssteel specimens with nanostructured $\mathrm{Al} / \mathrm{Ni}$ foils," Journal of Applied Physics, vol. 95, no. 1, pp. 248-256, 2004. 

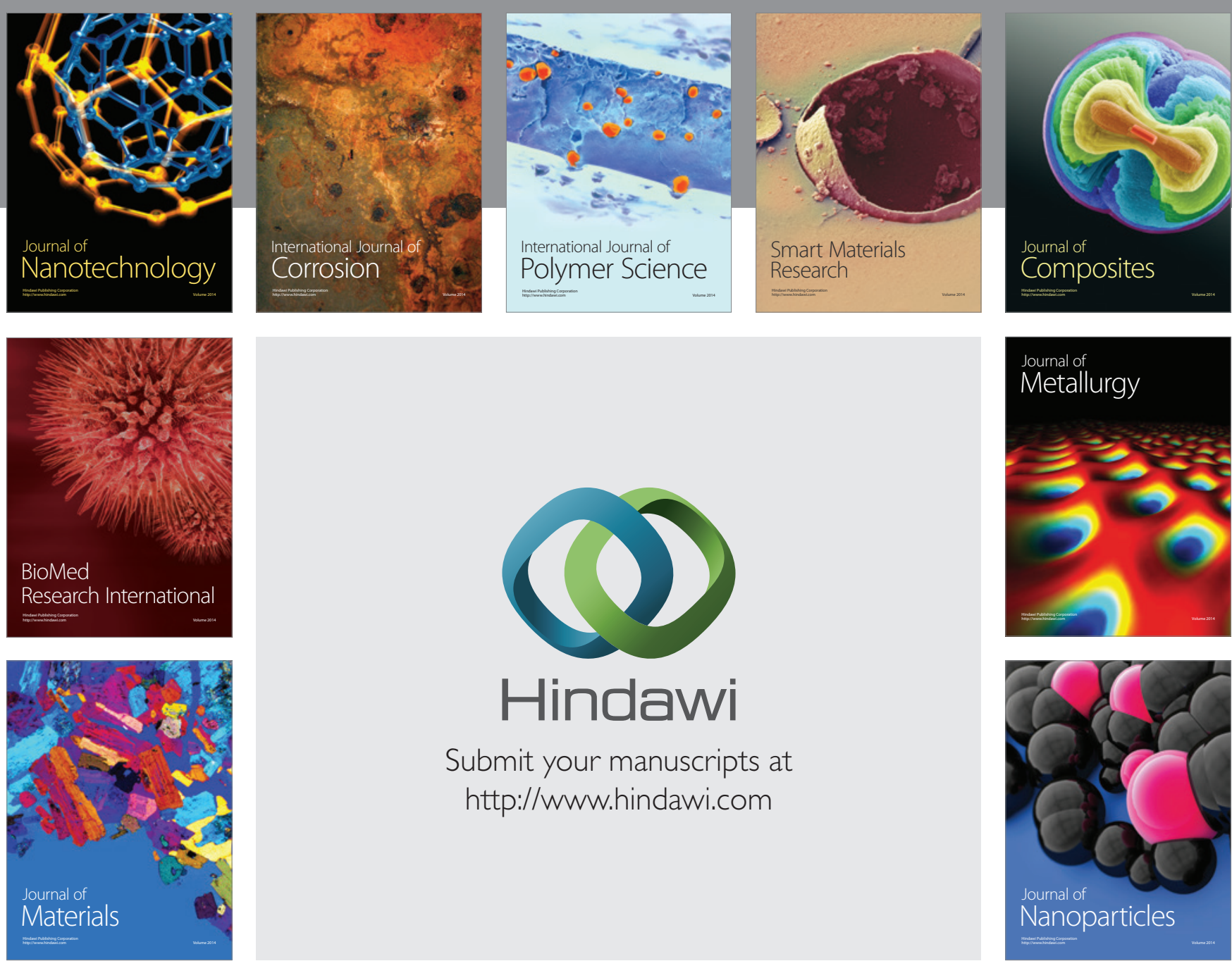

\section{Hindawi}

Submit your manuscripts at

http://www.hindawi.com

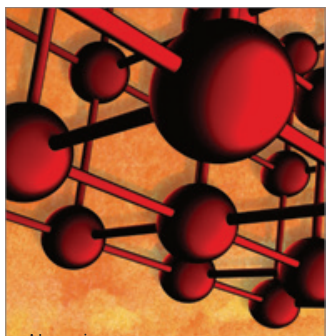

Materials Science and Engineering
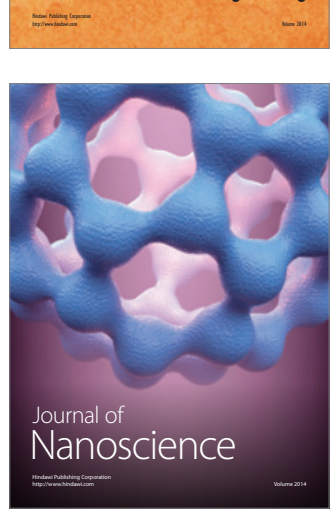
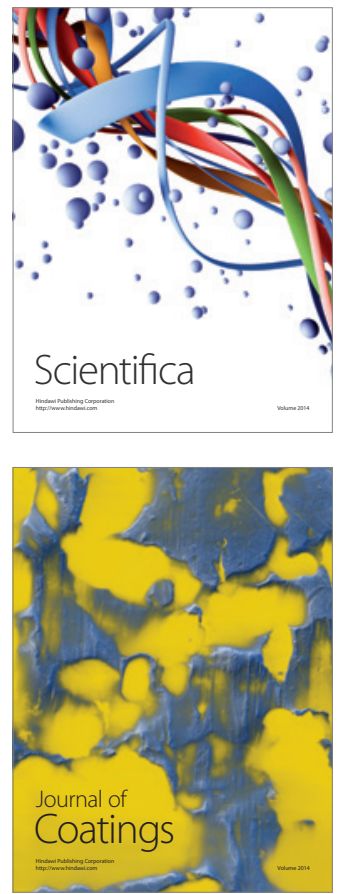
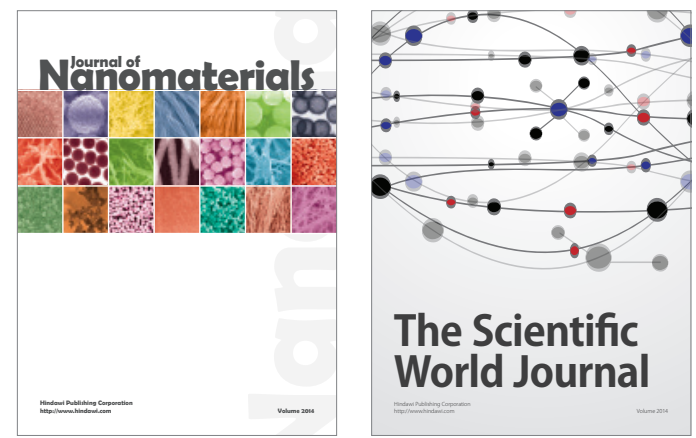

The Scientific World Journal
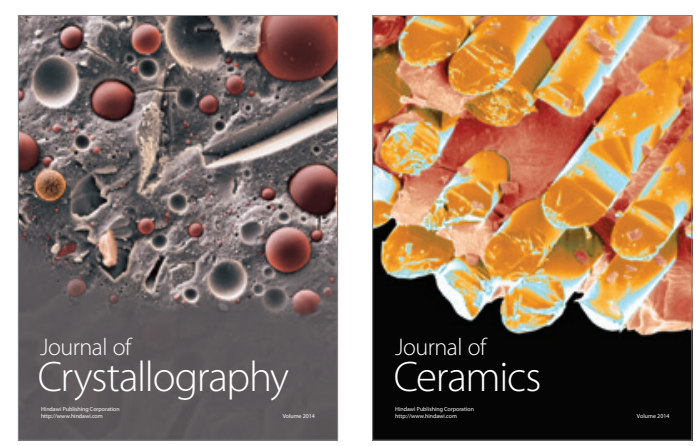
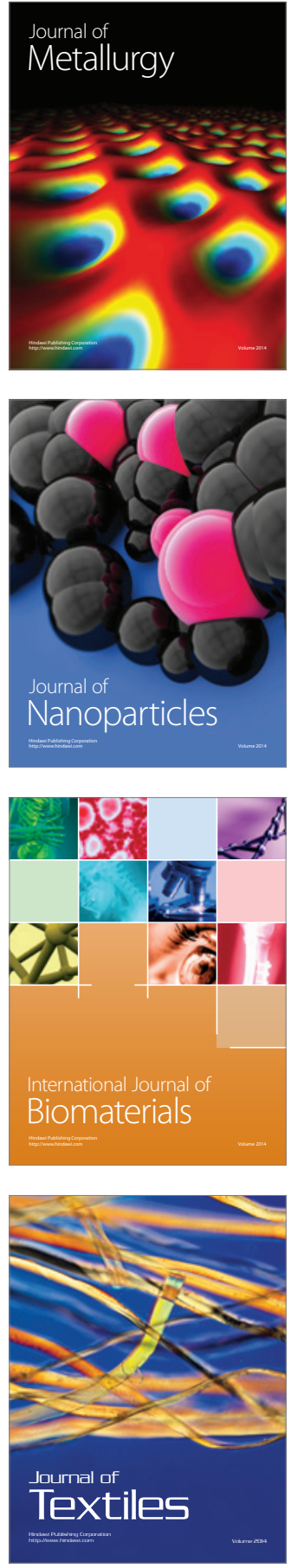